\title{
Vulnerability of U.S. Maize Germ Plasm to Phaeosphaeria Leaf Spot
}

\author{
M. L. Carson, Research Plant Pathologist, USDA-ARS and Associate Professor, Department of Plant Pathology, \\ North Carolina State University, Raleigh 27695-7616
}

\begin{abstract}
Carson, M. L. 1999. Vulnerability of U.S. maize germ plasm to Phaeosphaeria leaf spot. Plant Dis. 83:462-464.

Phaeosphaeria leaf spot (PLS) is a potentially important maize disease that has recently appeared in the continental United States in winter breeding nurseries in southern Florida. To better predict the potential of this newly introduced disease to inflict damage on the U.S. maize crop, 64 public and private inbred lines and 80 proprietary commercial maize hybrids representing the genetic diversity in the U.S. maize crop were evaluated for resistance to PLS in the 1996-97 and 1997-98 winter nursery seasons. Plots were evaluated for PLS severity (0 to 9 scale) at the early to mid dent stages of kernel development. Relatively few hybrids or inbreds were free from PLS at this growth stage. Inbred lines related to B73 were particularly susceptible to PLS. Relatively few commercial hybrids were as severely diseased as a susceptible check hybrid, indicating that U.S. maize production is not particularly vulnerable to damage from PLS at this time. However, the susceptibility of several widely used parental inbred lines makes PLS a potential concern to the seed industry should it become established in areas of hybrid seed production.
\end{abstract}

Phaeosphaeria leaf spot (PLS), caused by the ascomycete Phaeosphaeria maydis (Henn.) Rane, Payak, \& Renfro (anamorph = Phoma maydis, synonym = Leptosphaeria zea-maydis Saccas; Metasphaeria maydis (Henn.) Höhnel), is a potentially serious foliar disease of maize that is widely distributed in Central and South America, Asia, and Africa (4). The disease is most prevalent in areas of high rainfall and moderate temperatures, such as the higher elevations in the tropics. PLS is becoming an increasingly important disease of maize in South Africa (Elbe Smith, personal communication) and Brazil. PLS has occurred regularly in southern Florida winter maize breeding nurseries since at least 1990, and thus far this seems to be the limit of its distribution in the continental United States. Although there is little published information about PLS, its ability to cause damage to maize in other areas of the world makes the recent introduction of the disease to the United States a concern to seed producers and others.

Corresponding author: M. L. Carson

E-mail address: marty_carson@ncsu.edu

*The $e$-Xtra logo stands for "electronic extra," and indicates the HTML abstract available on-line contains supplemental material not included in the print edition.

Accepted for publication 5 February 1999.

Publication no. D-1999-0301-03R

This article is in the public domain and not copyrightable. It may be freely reprinted with customary crediting of the source. The American Phytopathological Society, 1999.
Initial observations of PLS in south Florida nurseries indicated that the inbred line B73 and its derivatives were particularly susceptible (1). Resistance to PLS in the inbred line Mo17 appears to be incompletely dominant and controlled by up to six QTLs (quantitative trait loci), based on mapping studies using recombinant inbred lines derived from the cross B73 $\times$ Mo17 (2). The purpose of this study was to assess the extent and degree of susceptibility to PLS of maize germ plasm representative of that occupying the majority of maize acreage in the United States.

\section{MATERIALS AND METHODS}

Germ plasm. A total of 64 inbred lines, including historically important and other miscellaneous public inbreds as well as currently grown, commercially important proprietary foundation inbred lines (supplied courtesy of Illinois Foundation Seeds, Inc., Champaign, IL, and Holden's Foundation Seeds, Inc., Williamsburg, IA) was selected for evaluation. Eighty commercial hybrids from the two largest hybrid seed producers in the United States were also selected for evaluation (seed provided courtesy Pioneer Hybrid Int., Inc., Johnston, IA, and Dekalb Genetics, Inc., Dekalb, IL). Collectively, this set of inbreds and hybrids is thought to be representative of the majority of maize germ plasm currently grown in the United States.

Experimental design. Inbred lines and hybrids were evaluated in separate experiments. Inbreds and hybrids were planted in early November 1996 and early December 1997 on a private farm near Homestead,
Florida. Each experiment consisted of a randomized complete block design with two replicates. Experimental units consisted of single rows, $4 \mathrm{~m}$ long and $0.9 \mathrm{~m}$ apart, with 20 seeds planted per plot. Plots were not thinned. In addition to the inbred lines and hybrids above, an experimental susceptible check hybrid (LB31 $\times$ an experimental inbred line, MMGPLS+) was included in each experiment. Plots were inoculated at the 8- to 10-leaf stage by placing approximately 20 to 30 kernels of sorghum grain cultures of $P$. maydis into the leaf whorls. Inoculum was prepared by soaking sorghum seed overnight in tap water, draining off the excess water, placing the seed in 1-liter flasks, and autoclaving for $1 \mathrm{~h}$. After flasks had cooled, they were inoculated with an aqueous suspension of 3-week-old corn leaf agar (CLA, 5) cultures of a Florida isolate (FL1) of P. maydis. Stock cultures were maintained as conidial suspensions in $15 \%$ glycerol at $-80^{\circ} \mathrm{C}$. Sorghum grain cultures were stored at $4^{\circ} \mathrm{C}$ until used. Plots were rated when the inbred line $\mathrm{B} 73$ was at the mid-dent growth stage. A 10-class rating system was used, where $0=$ no symptoms, $1 \cong 1 \%, 2 \cong 3 \%, 3 \cong 5 \%, 4 \cong 10 \%, 5 \cong$ $25 \%, 6 \cong 50 \%, 7 \cong 75 \%, 8 \cong 90 \%$, and $9=$ $100 \%$ leaf area spotted. Data were analyzed using ANOVA and the FLSD (0.05) statistic used to compare means. The genotype $\times$ year interaction term was significant in the combined analysis of inbred line reactions over years and was used as the error term in calculating the FLSD statistic for comparing inbred line means over years. The genotype $x$ environment interaction term was not statistically significant in the combined analysis of hybrid reactions. In addition, inbred lines were classified into recognized heterotic groups based on their pedigrees or genetic backgrounds (3), and the mean PLS reactions of those groups were compared using simple $t$ tests. An inbred line may have been represented in more than one heterotic group if indicated by its pedigree.

\section{RESULTS AND DISCUSSION}

The severity and development of PLS was significantly higher in the 1996-97 winter trials than in the 1997-98 trials. Average PLS ratings were 0.7 and 0.4 lower in 1997-98 trials for inbred lines and hybrids, respectively. Although six to seven inbred lines and six to nine hybrids had no symptoms (PLS rating $=0$ ) in each year, only three inbred lines and five hy- 
brids were disease free both seasons. Among inbred lines, a few had ratings greater than 7 ( $7 \cong 75 \%$ leaf area affected) in the 1996-97 trial, but none were rated

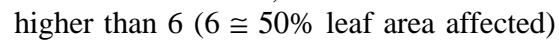
in 1997-98. The genotype $\times$ year interaction term was significant in the ANOVA of the inbred line trial, but not in the hybrid trial. However, the magnitude of the inbred line $x$ year interaction mean square was small in relation to that of the main effects of inbred lines. Much of the interaction appeared to be due to a few inbred lines that had much lower ratings in the 1997-98 trial than in the 1996-97 trial. For example, LH117 and LH172 had ratings of 4.5 and 4.0 in 1996-97, respectively, but both were rated 1.0 in 1997-98. Hybrids were generally much more resistant to PLS than inbred lines, with most rated less than 3 in both seasons $(3 \cong 5 \%$ leaf area affected $)$ (Fig. 1). Only two out of the 80 commercial hybrids (Pioneer Brand Hybrid 3489 and Dekalb Brand Hybrid DK641) and the susceptible check hybrid had mean PLS ratings of 5 or greater when the data over both seasons were combined (hybrid data available upon request from the author or in Plant Disease online).

When inbred lines were grouped according to their genetic background or heterotic pattern, the susceptibility of inbred lines related to B73 was apparent (Fig. 2). Inbred lines related to B73 were significantly less resistant to PLS than were those belonging to other heterotic groups. Although B73 is no longer commercially used, inbred lines tracing their parentage to B73 are widely used in the seed industry, usually as female or seed parent lines in hybrid seed production. Even within the B73 group, a few inbred lines such as LH227 and LH195 were fairly resistant to PLS (Table 1). Inbred lines related to $\mathrm{C} 103$, which are usually male or pollen parents in hybrid seed production, were as a group quite resistant to PLS, although a few, such as C123Ht, Va22, and LH210, were fairly susceptible. Inbred lines of Iowa Stiff Stalk Synthetic ancestry assignable to either the B37 or the B14 heterotic group and used as female parents in hybrids were as a group less susceptible than those in the B73 group.

Resistance to PLS appears to be at least partially dominant in crosses (2), and most commercial hybrids are single crosses of inbred lines of Iowa Stiff Stalk Synthetic origin with inbred lines of the C103 or other non-Stiff Stalk Synthetic origin. Therefore, it was not surprising that most commercial hybrids were fairly resistant to PLS in these trials. If PLS were to become established in the major maize production areas of the United States, losses probably would be slight, as the vulnerability of most current hybrids is quite low. At least two commercially significant hybrids were quite susceptible. Because of the lack of selection for resistance, it is possible for commercially successful but PLS susceptible hybrids to be marketed in the United States. A sig- nificant shift in the genetic base of hybrids toward susceptible germ plasm could result in an inadvertent increase in the vulnerability of the maize crop in the United States to PLS.

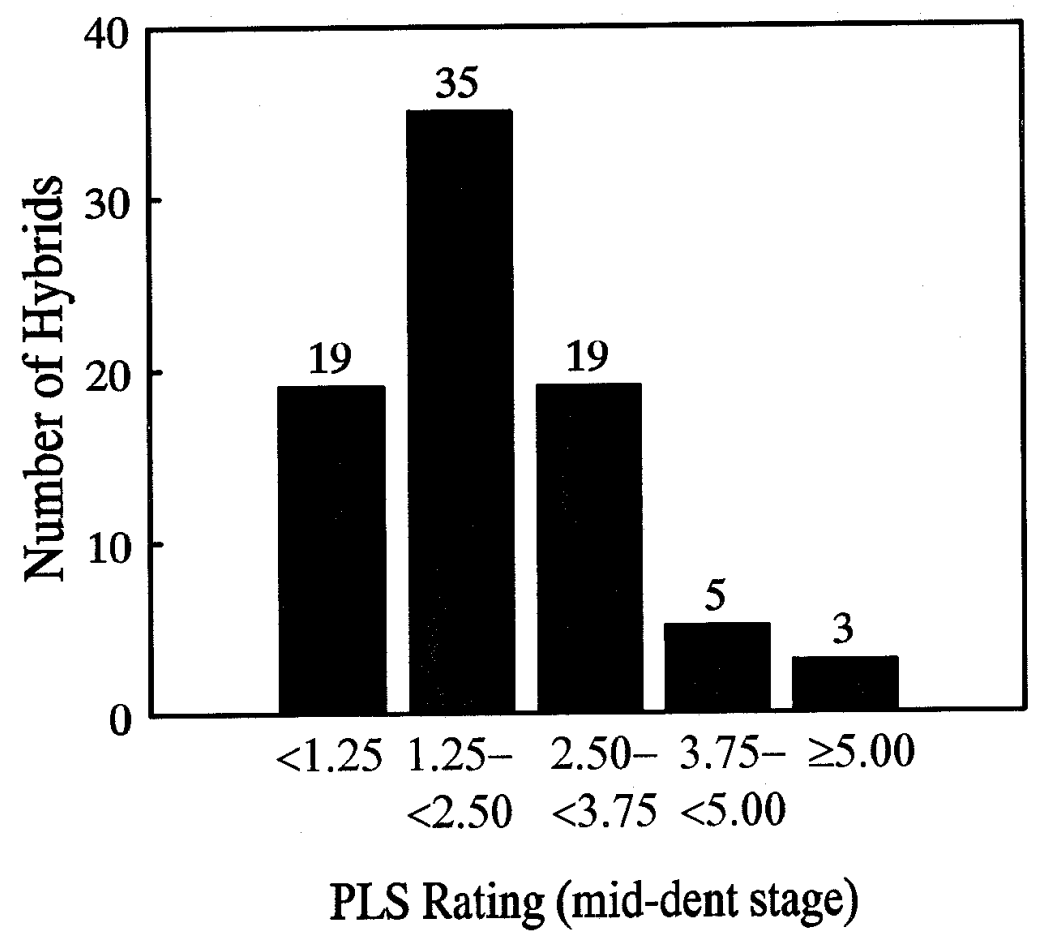

Fig. 1. Frequency distribution of mean Phaeosphaeria leaf spot severity ratings of commercial maize hybrids evaluated over two winter nursery seasons at Homestead, Florida.

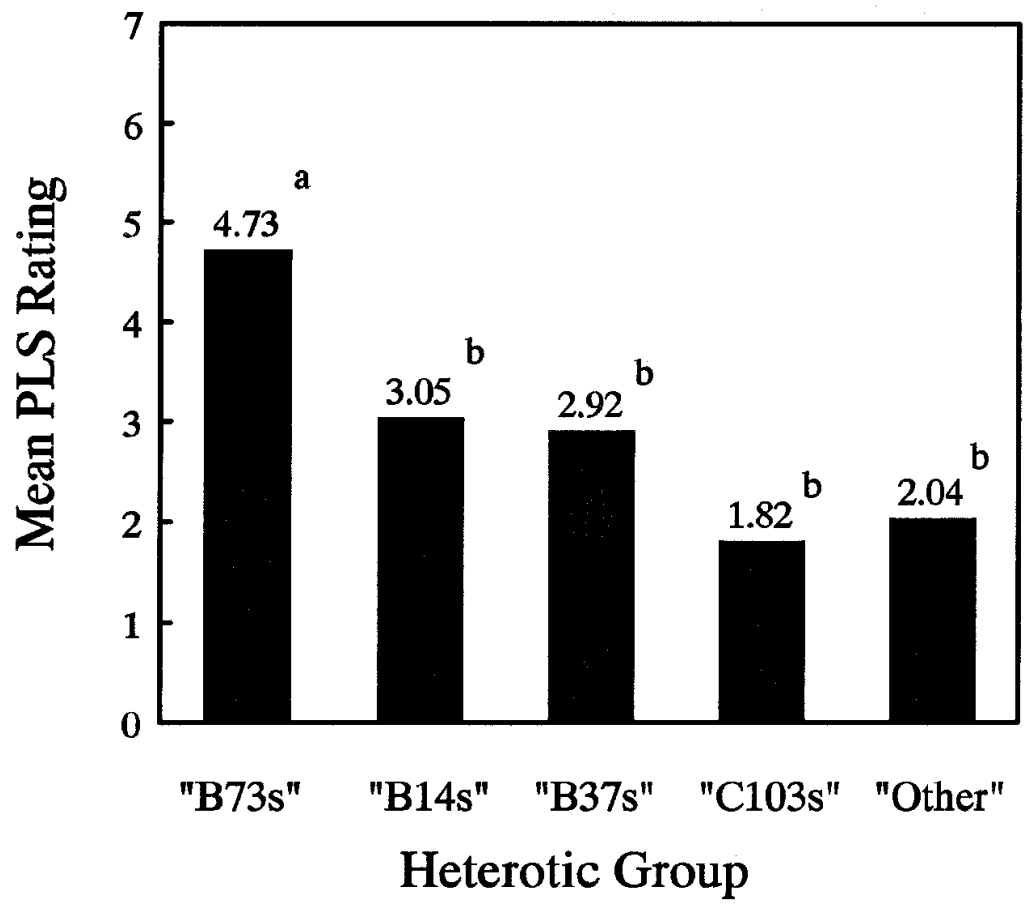

Fig. 2. Mean Phaeosphaeria leaf spot severity ratings of maize inbred lines representing different heterotic groups (based on pedigrees). Some inbred lines are represented in more than one group based on their mixed parentage. Means followed by the same letter are not significantly different based on simple $t$ tests $(P=0.05)$. 
Table 1. Mean Phaeosphaeria leaf spot ratings $(0$ to 9 scale where $0=$ no lesions and $9=100 \%$ leaf area blighted) of public and elite proprietary maize inbred lines evaluated over two winter nursery seasons at Homestead, Florida ${ }^{\mathrm{a}}$

\begin{tabular}{|c|c|c|c|}
\hline Public inbred lines & PLS rating & Proprietary inbred lines & PLS rating \\
\hline A556 (other) & 4.50 & FR140 (B14) & 0.25 \\
\hline A619 (other) & 0.00 & FR180 (other) & 3.25 \\
\hline $\mathrm{A} 632$ (B14) & 3.75 & FR460 (B14) & 1.50 \\
\hline B37 (B37) & 2.25 & FR667 (C103) & 1.00 \\
\hline $\mathrm{B} 37 H t 1 A(\mathrm{~B} 37)$ & 1.50 & FR808 (B73,B37) & 4.25 \\
\hline $\mathrm{B} 37 R p p 9$ (B37) & 1.50 & FR809 (B73,B37) & 5.00 \\
\hline $\mathrm{B} 68 H t N(\mathrm{~B} 14)$ & 0.25 & FR812 (C103) & 1.25 \\
\hline B73 (B73) & 6.50 & FR816 (other) & 0.25 \\
\hline $\mathrm{C} 123 \mathrm{Ht1}(\mathrm{C} 103)$ & 5.50 & FR902 (B14) & 4.00 \\
\hline Hi28 (other) & 0.75 & FR992 (B73) & 5.00 \\
\hline NC232 (other) & 1.50 & FR1064 (B73) & 6.00 \\
\hline NC258 (C103) & 0.00 & FR1075 (B73) & 5.25 \\
\hline NC296 (other) & 1.00 & FR1128 (B73) & 4.50 \\
\hline NC300 (other) & 3.50 & FR2352 (B73,B14) & 6.75 \\
\hline Oh07B (other) & 1.00 & FR4326 (C103) & 0.25 \\
\hline Pa91 (other) & 3.00 & LH51 (C103) & 0.50 \\
\hline RH95rhm (other) & 1.75 & LH59 (C103) & 0.25 \\
\hline SD10 (other) & 2.00 & LH74 (B73,B14) & 6.50 \\
\hline Tx303 (other) & 0.25 & LH82 (other) & 1.75 \\
\hline $\mathrm{Va} 22$ (C103) & 5.00 & LH93 (other) & 4.25 \\
\hline Va35 (C103) & 2.00 & LH117 (B73,B37) & 2.75 \\
\hline \multirow[t]{22}{*}{ W64AHt1 (other) } & 4.50 & LH122 (other) & 2.25 \\
\hline & & LH123 (other) & 0.25 \\
\hline & & LH132 (B73,B37) & 6.25 \\
\hline & & LH150 (other) & 2.25 \\
\hline & & LH172 (other) & 2.50 \\
\hline & & LH190 (B73,B14) & 6.00 \\
\hline & & LH192A (B73) & 5.25 \\
\hline & & LH195 (B73,B37) & 1.25 \\
\hline & & LH197 (B73) & 4.50 \\
\hline & & LH198 (B73) & 5.00 \\
\hline & & LH199 (B73,B37) & 3.25 \\
\hline & & LH200 (B73,B37) & 2.50 \\
\hline & & LH202 (B73) & 7.25 \\
\hline & & LH204 (B73,B14,B37) & 4.75 \\
\hline & & LH210 (C103) & 5.00 \\
\hline & & LH212 (C103) & 0.50 \\
\hline & & LH213 (C103) & 0.00 \\
\hline & & LH223 (B14) & 1.25 \\
\hline & & LH227 (B73,B14) & 2.25 \\
\hline & & LH235 (B73) & 3.25 \\
\hline & & LH252 (C103) & 2.50 \\
\hline & & LH262 (C103) & 1.75 \\
\hline Check hybrid & 4.75 & & \\
\hline $\operatorname{FLSD}(0.05)$ & 1.80 & & \\
\hline
\end{tabular}

${ }^{a}$ Heterotic group classification(s) of inbred lines is in parentheses.
Of more immediate concern is the vulnerability of hybrid seed production in the United States. Many widely used female seed parent inbred lines were quite susceptible to PLS. No estimates of potential yield losses associated with PLS are available, but it is likely that losses would be similar to those caused by other foliar blights of maize causing similar damage at the same plant growth stages. At this time, PLS has yet to be found in North America outside of southern Florida. Not enough is known about the biology of the disease or the pathogen to make predictions about its potential movement into and establishment in other maizeproducing areas of North America. Information on the spread, overwintering survival, alternate hosts, and basic epidemiology of the disease is needed. However, anecdotal evidence from other areas of the world where PLS occurs indicates that the disease causes notable damage and is of growing concern to maize pathologists and breeders.

\section{LITERATURE CITED}

1. Carson, M. L., Goodman, M. M., and Glawe, D. A. 1991. Phaeosphaeria leaf spot of maize in Florida. Plant Dis. 75:968.

2. Carson, M. L., Stuber, C. W., and Senior, M. L. 1996. Identification of quantitative trait loci (QTLs) for resistance to two foliar diseases in mapping population of recombinant inbred (RI) lines of maize. (Abstr.) Phytopathology 86:S59.

3. Gerdes, J. T., Behr, C. F., Coors, J. G., and Tracy, W. F. 1993. Compilation of North American Maize Breeding Germplasm. Crop Sci. Soc. Am., Madison, WI.

4. Rane, M. S., Payak, M. M., and Renfro, B. L. 1966. A Phaeosphaeria leaf spot of maize. Indian Phytopathol. Soc. Bull. 3:8-10.

5. Trainor, M. J., and Martinson, C. A. 1978 Nutrition during spore production and the inoculum potential of Helminthosporium maydis race T. Phytopathology 68:10491053. 